Case Report

\title{
Treatment of Bifocal Cyst Hydatid Involvement in Right Femur with Teicoplanin Added Bone Cement and Albendazole
}

\author{
Ozhan Pazarci, ${ }^{1}$ Zekeriya Oztemur, ${ }^{2}$ and Okay Bulut ${ }^{2}$ \\ ${ }^{1}$ Reyhanl State Hospital, 31000 Hatay, Turkey \\ ${ }^{2}$ Department of Orthopaedics and Traumatology, Cumhuriyet University School of Medicine, 58000 Sivas, Turkey \\ Correspondence should be addressed to Ozhan Pazarci; dr.pazarci@gmail.com
}

Received 7 February 2015; Revised 18 June 2015; Accepted 21 June 2015

Academic Editor: Athanassios Papanikolaou

Copyright (C) 2015 Ozhan Pazarci et al. This is an open access article distributed under the Creative Commons Attribution License, which permits unrestricted use, distribution, and reproduction in any medium, provided the original work is properly cited.

\begin{abstract}
Although bone involvement associated with cyst hydatid is rarely seen, it can cause unintended results such as high recurrence rate, infection, sepsis, or amputation of relevant extremity. Because of this reason, its treatment is difficult and disputed. In the case of bifocal bone cyst hydatid in right femur, along with albendazole treatment, result of resecting cyst surgically and its treatment with teicoplanin with added bone cement is given. In conclusion, since the offered treatment method both supports bone in terms of mechanical aspect and also can prevent secondary infection, the method is thought to be a good and safe treatment approach.
\end{abstract}

\section{Introduction}

Hydatid disease due to Echinococcus granulosus, which is a condition also known as echinococcosis, usually manifests as cysts in the liver and lungs, but the larvae of this tapeworm can lodge anywhere in the body [1]. Skeletal involvement of $E$. granulosus is rare, occurring in only $0.28-3.1 \%$ of hydatidosis cases [1]. In a study, localisation of echinococci in the bone was reported in vertebra as 30\%, in pelvis and hip as $20 \%$, in femur and tibia as $15 \%$, in humerus as $15 \%$, and in phalanx as $5 \%$ [2]. There are difficulties in the diagnosis and treatment of cyst hydatid with bone involvement $[3,4]$.

In the reported case, combination of filling the cavity, which forms after the curettage of cyst and chlorhexidine washing, with antibiotic-loaded bone cement and albendazole treatment is discussed as a new approach for the treatment of bifocal cyst hydatid in femur.

\section{Case}

A 17-year-old female patient has a pain complaint in her hip and femur, which has increased especially during nights and by activity for almost three years and has also awoken the patient from sleeping. She had no known disease in her background; however, she had a story of keeping a dog in her house ten years ago. The patient was hitching during physical examination. Range of motion of right hip was full, and there was minimal pain in her hip movements. There were pain and sensitivity in right proximal and distal femur by pressure.

In the direct radiography, a cystic lesion with approximately $4 \times 4 \mathrm{~cm}$ geographical borders displaying extension from right femur intertrochanteric area to subtrochanteric area was monitored (Figure 1). There was a cystic lesion which displays extension to the medial cortex with approximately 3 $\times 1 \mathrm{~cm}$ geographical borders in the right femur distal medial (Figure 1). In MRI, cystic mass lesion having multiloculated, trabecula, expansile characteristic and cystic lesion including septation with $6 \times 2 \mathrm{~cm}$ lobule contour in right femur distal diaphysis along with apparent destruction in bone cortex are observed in the localization of right femur trochanter major, intertrochanteric area and femur $1 / 3$ proximal diaphysis (Figure 2). Soft-tissue plans surrounding lesion were normal.

In the laboratory, sedimentation was 46 , C-reactive protein was 1.28 , white blood cell count was 7700 , and indirect hemagglutination test was $+(1 / 320)$. In the case, thought to have prediagnosis of cyst hydatid, abdominal and hepatobiliary ultrasonography, thorax computerised tomography, chest radiography, and vertebra radiography were evaluated as normal.

Proximal lesion was reached by opening approximately $2 \times 6 \mathrm{~cm}$ cover from femoral cortex. After the curettage, forming cavity was washed with $4 \%$ chlorhexidine for 10 


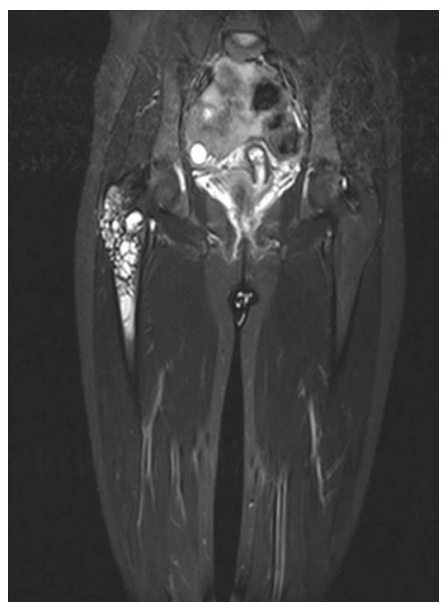

(a)

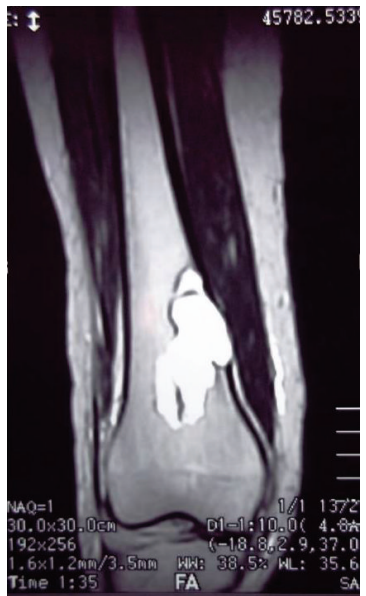

(b)

FIGURE 1: Preoperative MR images.

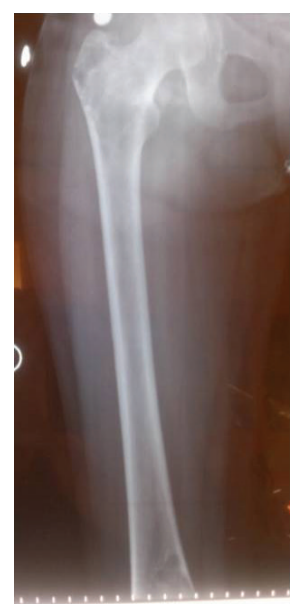

(a)

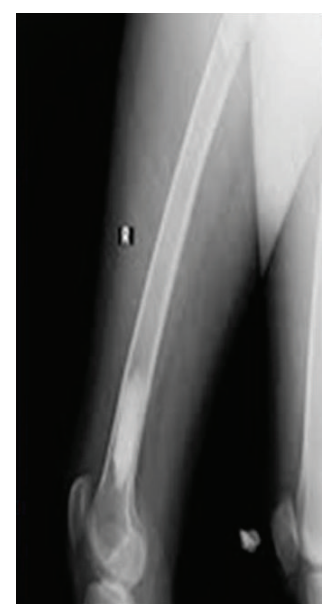

(b)

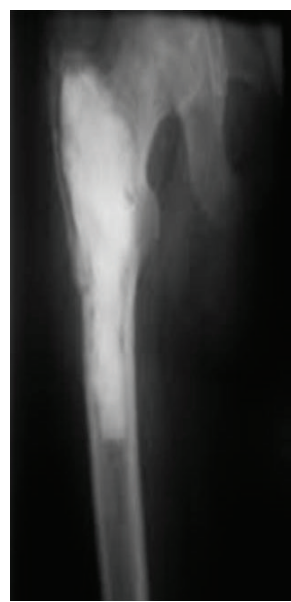

(c)

FIGURE 2: Preoperative and postoperative radiographs.

minutes and then filled with 40 gr bone cement with addition of $1200 \mathrm{mg}$ teicoplanin in order to prevent the secondary infection. In the pathological examination, cuticula of cyst hydatid and its scolexes were observed and the treatment of albendazole $2 \times 400 \mathrm{mg} /$ day was started. Lesion in femur distal was cured after 14 days and was washed with $4 \%$ chlorhexidine and filled with bone cement. After that, albendazole treatment was completed in 28 days.

After the surgery, any problem regarding lesion area was not observed during follow-up; on the third month full weight was given to the patient, who was pressed by partial weight-bearing with crutches on the post-op second month. No complication was observed during the treatment except for minimal increase in liver enzymes and movement disability in the knee. After active/passive exercise program aimed at range of motion of knee joint, full range of motion was provided. During follow-ups made in the first and third year after treatment, no recurrence and serious complication were seen.

\section{Discussion}

The study conducted by Papanikolaou et al. [5] reported that bone involvement rate was between $0.2 \%$ and $4 \%$ and the great majority of them had vertebra involvement. In contrast to the case who has complaint of chronic hip pain, it is an insidious disease until complications such as paraplegia and pathological fracture develop [6]. As is in the reported case, the diagnosis is generally established intraoperatively. Preoperative radiological and serologic diagnosis methods are deprived of high sensitivity and specificity. Particularly in the cases with nonunion pathological fractures, having cystic lesions on any place of their bodies in endemic areas, diagnosis should be kept in mind [7].

Surgical treatment only may not be successful because of the difficulty of total excision and may increase the risk of dissemination. Recently treatment of osseous hydatid disease has been entirely surgical, and the aims are removal of the cyst and surrounding bone, replacement of bone defects 
with bone grafts or a prosthesis, avoidance of secondary infection, and prevention of recurrence [8-10]. Ideally, the lesions should be removed using the same technique in case of a malignant tumour [11, 12]. When the lesions are too extensive to allow complete excision, curettage and/or aspiration of a painful cyst are performed [11, 13], and chemotherapy effective against E. granulosus is given to prevent recurrences [11]. Clinical trials using benzimidazole compounds have shown promising but variable results. Both albendazole and mebendazole have demonstrated efficacy. A slightly greater efficacy related to rates of complete cure and improvement has been obtained with albendazole [14, 15]. We performed 28 days of treatment with albendazole. Different treatments have been described in the literature. Oxfendazole at $60 \mathrm{mg} / \mathrm{kg}$ and the combined therapies of oxfendazole + praziquantel $(30 \mathrm{mg} / \mathrm{Kg}+40 \mathrm{mg} / \mathrm{Kg})$ and albendazole + praziquantel $(30 \mathrm{mg} / \mathrm{Kg}+40 \mathrm{mg} / \mathrm{Kg})$ are successful agents that can be added to current control measures to interrupt the transmission of Echinococcus granulosus. It also demonstrates the potential of these antiparasitic drugs to be used in the treatment of cystic echinococcosis in a relatively short period of time, reducing the cost of the therapy [16]. They conclude that, in the future, combined therapy with praziquantel and albendazole could be successfully applied to humans as preoperative treatment, thereby avoiding accidental dissemination, due to the combination's protoscolicidal action [17].

In multiple bone involvements especially together with pelvis and hip involvement, infestation recurrence, sepsis, amputation, unsatisfactory results, and, also the worst of all, death complications are reported [18, 19]. For this reason, treatment planning and follow-up of multiple bone involvements are very important. In the reported case, there was bifocal cyst hydatid localisation in femur (Figure 2). When the treatment of the case is planned, it is considered that, especially for lesions on the same bone, there is a high possibility of development of pathological fracture during curettage or after the surgery. It was possible to provide a mechanical support by using an orthopaedic implant; however, it was planned to fill the cysts with bone cement after curettage procedure because of secondary infection risk.

It is postulated that the exothermic reaction of methylmethacrylate generates local hyperthermia which induces necrosis of surrounding tissue. The theory cannot exclude the possibility that the polymerisation of methylmethacrylate may produce a local chemical cytotoxic effect [20]. Cementation using methylmethacrylate has shown encouraging results in therapy of giant cell tumours of bone before [20]. Yildiz et al. [21] reported 15 cases of bone hydatidosis; ten of the patients had had surgery before in other clinics due to bone and/or soft-tissue lesions and suffered relapses which required further treatment. They performed curettage, swabbing with povidone iodine, and filling the defect with polymethylmethacrylate (PMMA) in 10 patients. Three of these had a recurrence after 5 years, but seven had no signs of relapse during a mean follow-up of 52 months. Different from that study, in our case, we tried to prevent infection and sepsis, which are the most serious complications, by providing highly antibiotic concentration around cyst as well as the mechanical support after curettage by adding teicoplanin to bone cement.

As a result, in infestations of cyst hydatid localised in the long bone, since filling the cyst with antibiotic-loaded bone cement after curettage of the cyst and washing it with chlorhexidine or betadine along with albendazole treatment can both support the bone mechanically and prevent the secondary infection, we consider the method as a good and safe treatment approach.

\section{Conflict of Interests}

The authors declare that there is no conflict of interests regarding the publication of this paper.

\section{References}

[1] A. Pourbagher, M. A. Pourbagher, M. A. Hersekli, and L. Savas, "Humeral hydatid cyst mimicking a malignant bone tumor," European Journal of Radiology Extra, vol. 55, no. 3, pp. 89-92, 2005.

[2] M. Schneppenheim and J. Jerosch, "Echinococcosis granulosus/cysticus of the tibia," Archives of Orthopaedic and Trauma Surgery, vol. 123, no. 2-3, pp. 107-111, 2003.

[3] M. Arazi, M. Erikoglu, K. Odev, R. Memik, and M. Ozdemir, "Primary echinococcus infestation of the bone and muscles," Clinical Orthopaedics and Related Research, no. 432, pp. 234241, 2005.

[4] M. K. Booz, "The management of hydatid disease of bone and joint," The Journal of Bone \& Joint Surgery Series B, vol. 54, no. 4, pp. 698-709, 1972.

[5] A. Papanikolaou, N. Antoniou, D. Pavlakis, and G. Garas, "Hydatid disease of the tarsal bones. A case report," Journal of Foot and Ankle Surgery, vol. 44, no. 5, pp. 396-400, 2005.

[6] A. Papanikolaou, "Osseous hydatid disease," Transactions of the Royal Society of Tropical Medicine and Hygiene, vol. 102, no. 3, pp. 233-238, 2008.

[7] R. Siwach, R. Singh, V. K. Kadian et al., "Extensive hydatidosis of the femur and pelvis with pathological fracture: a case report," International Journal of Infectious Diseases, vol. 13, no. 6, pp. e480-e482, 2009.

[8] X. H. Song, L. W. Ding, and H. Wen, "Bone hydatid disease," Postgraduate Medical Journal, vol. 83, no. 982, pp. 536-542, 2007.

[9] A. Herrera and A. A. Martinez, "Extraspinal bone hydatidosis," The Journal of Bone \& Joint Surgery -American Volume, vol. 85, no. 9, pp. 1790-1794, 2003.

[10] A. Herrera, A. A. Martínez, and J. Rodríguez, "Spinal hydatidosis," Spine, vol. 30, no. 21, pp. 2439-2444, 2005.

[11] H. Loudiye, S. Aktaou, H. Hassikou et al., "Hydatid disease of bone: review of 11 cases," Joint Bone Spine, vol. 70, no. 5, pp. 352$355,2003$.

[12] N. Bergaoui, M. Ben Hammouda, M. Touzi et al., "Costal and extra-dural dorsal localisation of hydatidosis," Rhumatologie, vol. 48, no. 6, pp. 207-211, 1996.

[13] J. P. Franceschi, G. Curvale, P. Noca, and H. Roux, "Kyste hydatique du bassin. À propos d'un cas suivi sur 8 ans," Revue du Rhumatisme, vol. 58, pp. 211-213, 1991.

[14] A. El Kohen, A. Benjelloun, A. El Quessar et al., "Multiple hydatid cysts of the neck, the nasopharynx and the skull base revealing cervical vertebral hydatid disease," International 
Journal of Pediatric Otorhinolaryngology, vol. 67, no. 6, pp. 655662, 2003.

[15] K. Gangopadhyay, M. O. Abuzeid, and H. Kfoury, "Hydatid cyst of the pterygopalatine-infratemporal fossa," The Journal of Laryngology \& Otology, vol. 110, no. 10, pp. 978-980, 1996.

[16] C. M. Gavidia, A. E. Gonzalez, E. A. Barron et al., "Evaluation of oxfendazole, praziquantel and albendazole against cystic echinococcosis: a randomized clinical trial in naturally infected sheep," PLoS Neglected Tropical Diseases, vol. 4, no. 2, article e616, 2010.

[17] M. A. Urrea-París, M. J. Moreno, N. Casado, and F. RodriguezCaabeiro, "In vitro effect of praziquantel and albendazole combination therapy on the larval stage of Echinococcus granulosus," Parasitology Research, vol. 86, no. 12, pp. 957-964, 2000.

[18] A. Massè, P. G. Parola, E. M. B. del Prever, and P. Gallinaro, "Hydatidosis of the pelvis: a case report with a 25-year folllowup," Archives of Orthopaedic and Trauma Surgery, vol. 124, no. 3, pp. 203-205, 2004.

[19] S. Agarwal, A. Shah, S. K. Mohammed Kadhi, and R. J. Rooney, "Hydatid bone disease of the pelvis. A report of two cases and review of the literature," Clinical Orthopaedics and Related Research, no. 280, pp. 251-255, 1992.

[20] A. Puri and M. Agarwal, "Treatment of giant cell tumor of bone: current concepts," Indian Journal of Orthopaedics, vol. 41, no. 2, pp. 101-108, 2007.

[21] Y. Yildiz, K. Bayrakci, M. Altay, and Y. Saglik, "The use of polymethylmethacrylate in the management of hydatid disease of bone," The Journal of Bone \& Joint Surgery Series B, vol. 83, no. 7, pp. 1005-1008, 2001. 


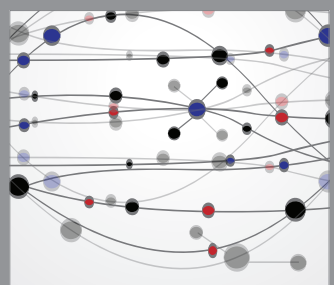

The Scientific World Journal
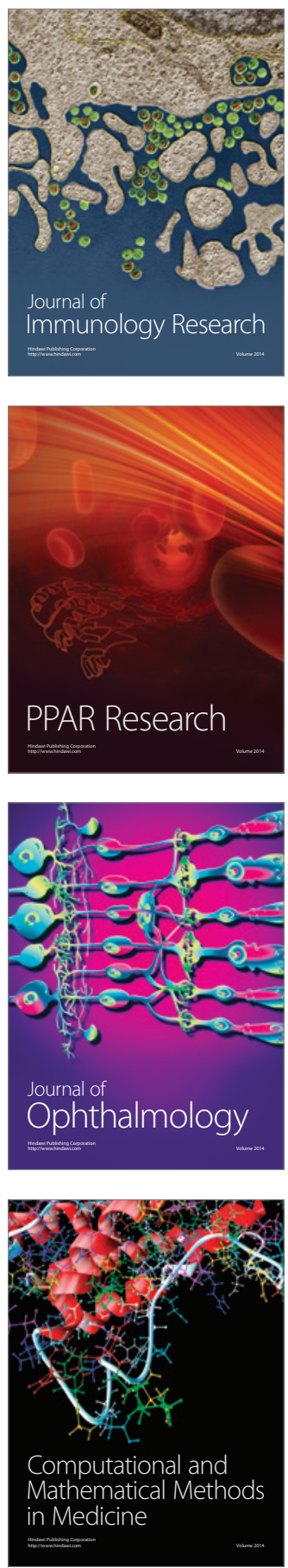

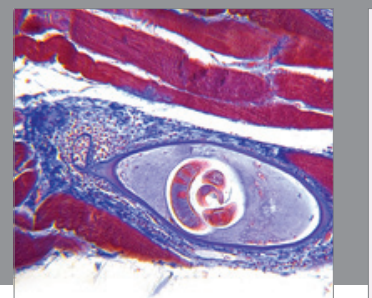

Gastroenterology

Research and Practice
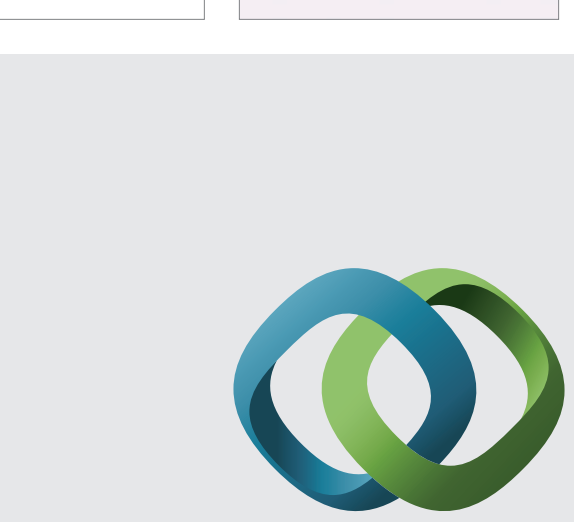

\section{Hindawi}

Submit your manuscripts at

http://www.hindawi.com
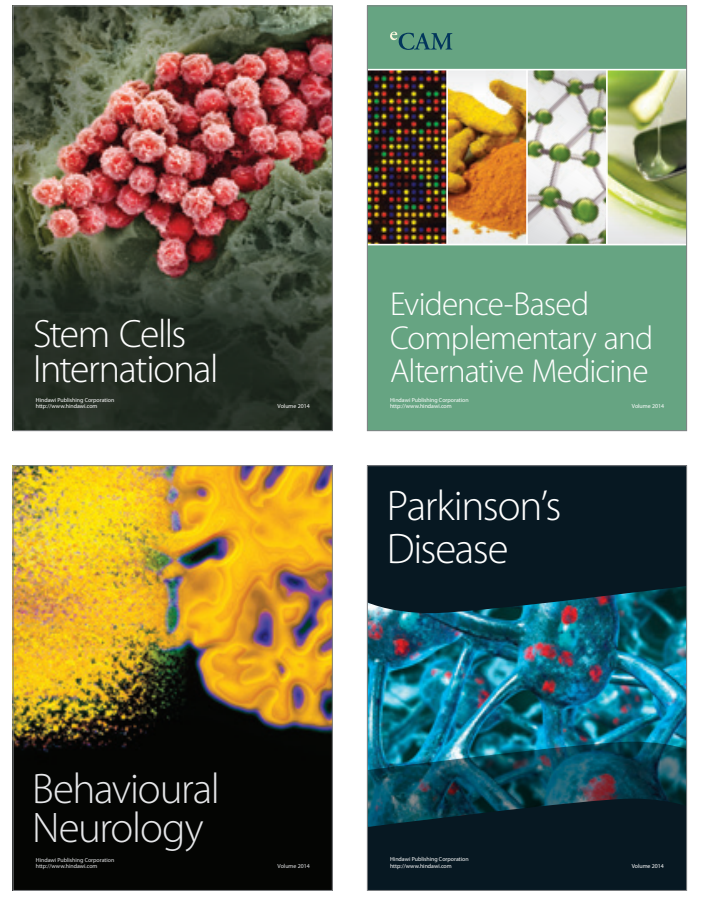
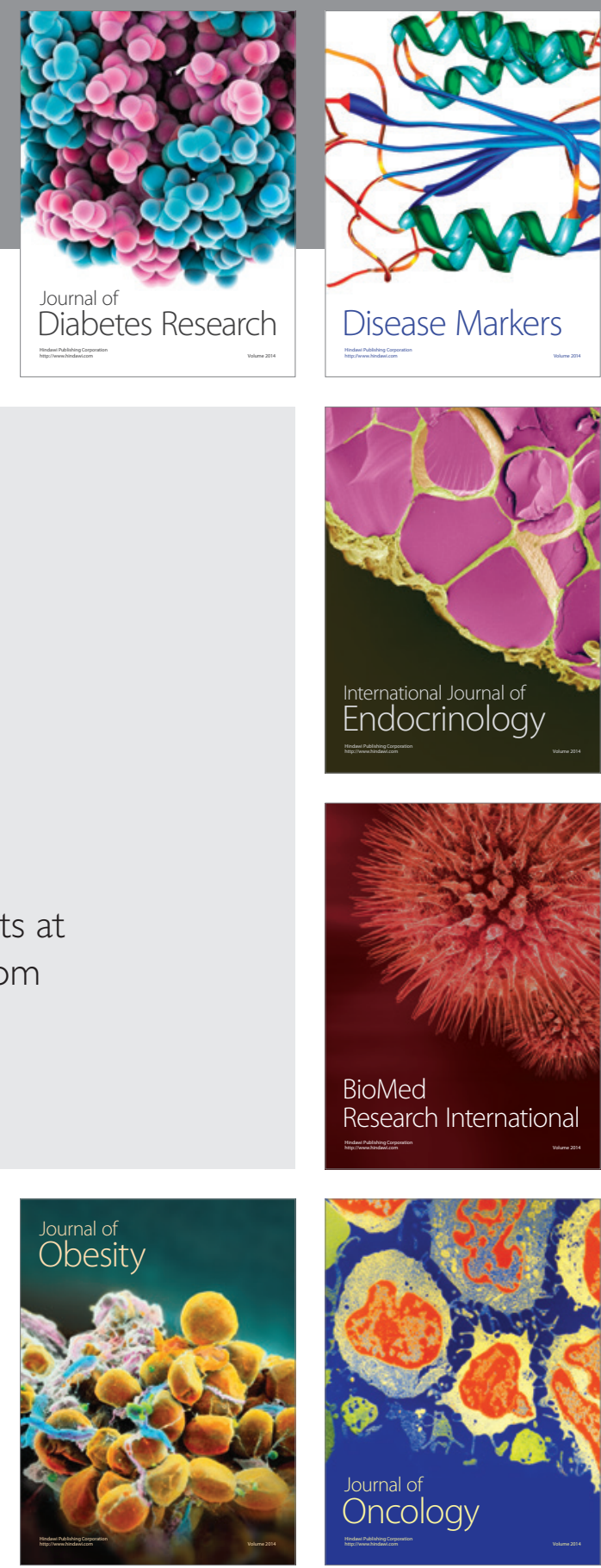

Disease Markers
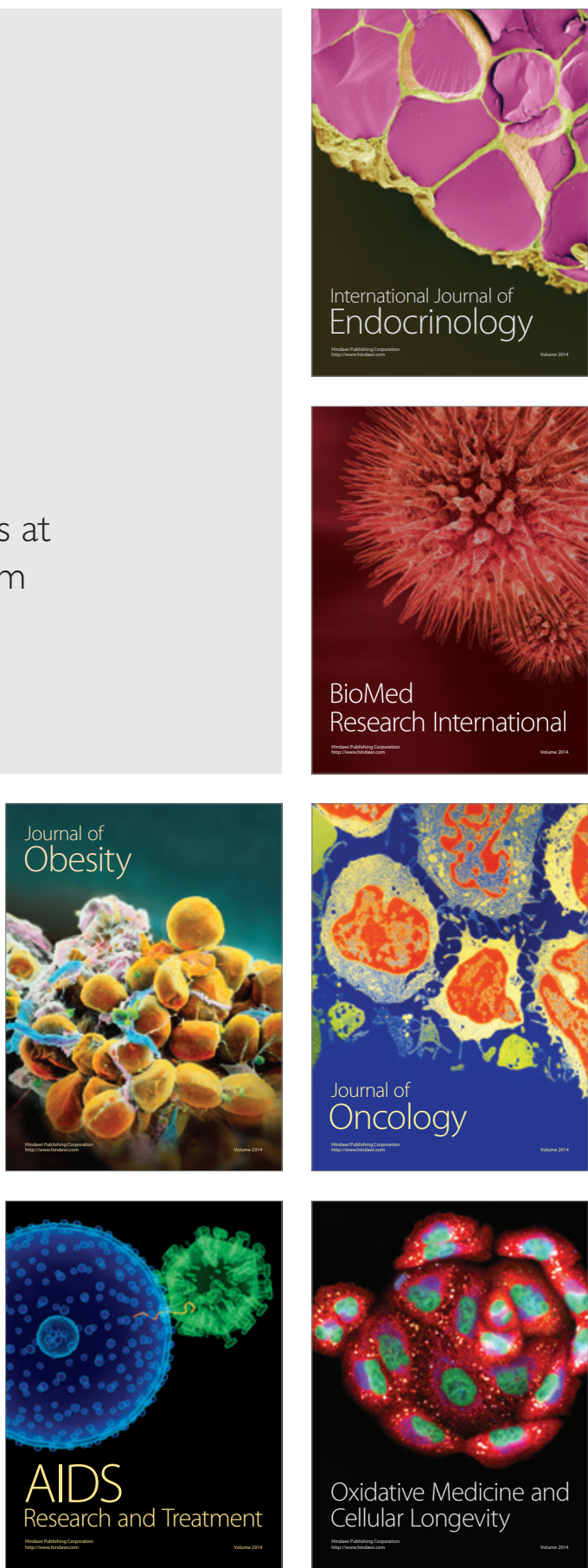